\title{
Effects of Discontinuing Contact Precaution on Control of Extended-Spectrum $\beta$-lactamase- producing Enterobacteriaceae Nosocomial Acquisition: An Interrupted Time Series Analysis
}

\section{Marie Regad ( $\nabla$ m.regad@chru-nancy.fr )}

Universite de Lorraine https://orcid.org/0000-0003-0572-6508

\section{Laurie Renaudin}

Hopital de Mercy

Julie Lizon

CHRU de Nancy: Centre hospitalier regional universitaire de Nancy

\section{Bruno Levy}

CHRU de Nancy: Centre hospitalier regional universitaire de Nancy

Caroline Jacquet

CHRU de Nancy: Centre hospitalier regional universitaire de Nancy

Arnaud Florentin

CHRU de Nancy: Centre hospitalier regional universitaire de Nancy

\section{Research}

Keywords: Extended-spectrum Beta lactamase Enterobacteriaceae, Interrupted Time series, Standard Precaution

Posted Date: September 4th, 2020

DOI: https://doi.org/10.21203/rs.3.rs-69361/v1

License: (a) (i) This work is licensed under a Creative Commons Attribution 4.0 International License. Read Full License 


\section{Abstract \\ Background:}

Interest of contact precautions (CP) to prevent cross-transmission in addition to standard precautions $(\mathrm{SP})$ is actually debated in the literature for some microorganisms, like extended-spectrum $\beta$-lactamaseproducing Enterobacteriaceae (ESBLE). We took advantage of the decision to stop CP for ESBLE in our hospital to study in real life if this discontinuing has an impact on the ESBLE acquisition rate.

\section{Methods:}

An interrupted time series (ITS) was performed in 3 wards and the week was used as the temporal unit. The ESBLE acquisition and importation incidence density (ID) and potential risks factors (colonization and selective pressure, Alcohol-Based hand rub solution consumption rates, demographic patients data) were collected between two periods: the pre-intervention (July 2018 to June 2019) when patients infected or colonized by ESBLE were cared with PC and SP and the post-intervention (September 2019 to March 2020) when patients were cared with SP only.

\section{Results:}

ESBLE acquisition ID were of $1.32 \pm 1.36$ and $1.17 \pm 1.25$ cases per 1000 patient-days for the pre- and post-intervention period respectively with no significant change in slope $(p=0.15)$. The only confounding variable significant $(p=0.04)$ in ITS was the antibiotics consumption, with a positive increasing trend.

\section{Conclusion:}

This study showed that the SP alone in order to control the ESBLE nosocomial did not lead to increasing the ESBLE nosocomial cross-transmission.

\section{Introduction}

Extended-spectrum beta-lactamase-producing Enterobacteriaceae (ESBLE) infections have been steadily rising since the 2000s. These infections represent a real issue in the healthcare settings, since they increase healthcare costs, length of stay (LOS) and are a cause of mortality worldwide (1). In 2017, the incidence density (ID) of ESBLE in French hospitals reached 0.62 per 1000 patient days, while the ID of methicillin-resistant Staphylococcus aureus (MRSA) continued to decreased to 0.23 per 1000 patients days (2).

International and national guidelines to prevent the spread of multidrug-resistant organisms (MDRO) within hospitals include two ways : limiting the emergence of resistance through the antimicrobial 
stewardship (3) and preventing the transmission of a resistant species between patients through the respect of barrier measures. These consist of standard precautions (SP) and transmission-based precautions like contact precautions (CP) in order to reduce microorganisms' cross-transmission. CP bundles usually involve the use of a single-bed room, patient-dedicated equipment, carriage signalization and to wear an apron for healthcare workers (HCWs) during direct contact with colonized or infected patients. (4) CP has been used for years and still allow today the control of microorganisms' crosstransmission such as Clostridium difficile or extremely drug resistant bacteria (5).

ESBLE are spreading not only in the hospital but also in the community. In France, the incidence density of Escherichia Coli BLSE samples from all sites increased from 0.2 per 1000 patient days in 2001 to 3.9 per 1000 patient days in 2017 (6). The CP contribution compared to SP and their global impact are debated. Indeed, many studies suggest that CP are related to an increased rate of anxiety and depression patient symptoms, decreasing patient satisfaction with care (7) and an increased rate of adverse events associated with $\mathrm{CP}(8)$, notably due to a lack of patient HCWs contact. In addition to the substantial burdens on hospital resources, when CP are required for HCWS teams (9).

Lastly, Enterobacteriaceae are present in the intestinal human tract and are part of the commensal gut flora. The two mains preventing measures against this type of microorganism cross transmission are management of excreta and hand hygiene $(\mathrm{HH})$, both part of SP (10). In other words, compliance and strict application of SP may be the strategy to prevent ESBLE transmission.

In June 2019, the decision to discontinue CP for EBLSE infected or colonized patients (except for the respiratory site where additional "droplet" precautions are still maintained) was taken by our infection prevention and control team. We took advantage of the practices change and the opportunity to place ourselves in real conditions to set up our study.

The aim of this study was to determine if the SP alone by discontinuing CP does not increase the acquired ESBLE density incidence, our main outcome.

\section{Material And Method}

\section{Study design}

The present study was conducted from July 2018 to March 2020 at a 1667-bed teaching hospital in France. The period study was divided into three phases: the pre-intervention period defined as July 2018 through June 2019 (52 weeks), the intervention period extended from July to September 2019 (8 weeks) and the post-intervention period defined as September 2019 through March 2020 (27 weeks). The week was defined as the temporal unit.

During the pre-intervention phase, the patients colonized or infected with EBLSE were assigned to receive care under $\mathrm{CP}$ in addition of SP. The intervention phase consisted to inform HCWs about the ESBLEs, the new recommendations about discontinuing PC for the ESBLE colonized or infected patients and the SP'S 
awareness. This information was performed by the Infection prevention and control team (IPCT) either by an intern or a nurse. During the post-intervention phase, strict application of SP was applied for all patients expected for patients who CP was indicated according to the hospital's infection control and isolation policies.

\section{Population}

Systematic fecal screening for ESBLE colonization is performed at the stage of admission and weekly for patients hospitalized in the adult Intensive Care Units (ICU) and hematology ward. The main interest is to guide the empiric treatment of acquired infections because of the suspected link between colonization and infection $(11,12)$.

All patients admitted for more than 48 hours in the ICU and hematology ward during the study period were included. A patient was included for each of his hospital stay.

\section{Data collection}

Patient, microbiological, antibiotic consumption and hand hygiene compliance data were collected:

- Patient demographic and risk factors information from the computerized records system. Clinical data were collected retrospectively: gender, age, admission Acute Physiology and Chronic Health Evaluation (APACHE), the LOS.

- Microbiological data:

- History of ESBLE carriage,

- Results of ESBLE research at an early stage of admission and on a weekly basis. In case of positive culture, we were studying the type of organism, site of infection or colonization, documented history of ESBL-positive organisms,

- Completeness of swabs: number of rectal swabs performed divided by the number of expected swabs,

- The incidence density (ID) rate, was calculated, where the incidence represents the number of patients infected by an ESBLE (infection or colonization) divided by the cumulative duration of stay of all potentially exposed patients.

A positive rectal swab within the 48 hours following admission the ESBLE case was considered as an imported carriage; whereas a positive surveillance swab for patients with a negative admission sample was considered as a nosocomial or acquired acquisition.

Then, the acquisition ID, our main outcome variable, was reported to the number of acquisitions per 1,000 patient days a week. We did the same for the importation ID.

- "Colonization pressure" i.e., the number of patients colonized or infected during the week divided by the number of patients treated during the week. Colonization pressure is indeed a risk factor for cross-transmission acquisition of ESBLE if it is higher than or equal to $10 \% .(15,16)$ 
- Hand hygiene compliance: as a surrogate, we used the French index of Alcohol-Based Hand Rub (ABHR) solution consumption, requested by the French Ministry of Health (13) and defined by the French National Authority for Health. This indicator is the ratio between the ward consumption (in liters) provided by the pharmacy database divided by hypothetical consumption, defined by opportunities of hand disinfection during an patient day depending on the ward specialty (For example 43 minimum opportunities for hand rubbing per patient per day in ICUs) (14). We reported the index per month.

- Antibiotic consumption: we calculated monthly the antibiotic exposure in Defined Daily Dose (DDD) from the pharmacy database and the denominator: exposed population. The DDD are expressed per 1,000 patient days.

\section{Data Analysis}

The univariate analysis consisted of a descriptive analysis: continuous quantitative variables were presented by means and standard deviations and qualitative variables were exposed by absolute and relative frequencies in order to study the distributions of our data. The quantitative variables were compared with Student tests and the qualitative variables were compared with Chi2 tests.

Weekly trends in ESBLE infection/colonization's incidence density were plotted to highlight and characterize patterns of change.

We used a single interrupted time series (ITS) analysis (SITSA), to assess the changes in ESBLE incidence density before and after the CP's discontinuing. The ITS allows a quasi-experimental approach for evaluating longitudinal intervention's effects and the segmented regression is particularly useful for assessing the impact of policy or some other healthcare initiative. Residuals were tested for autocorrelation by Durbin-Watson test. The SITSA model follows the regression:

$y=\beta_{0}+\beta_{1} T+\beta_{2} X+\beta_{3} T x$

Where $y=$ outcome variable, $\beta_{0}$ the baseline at $T=0, \beta 1$ represents the underlying pre-intervention trend, $\beta_{2}$ the level change following the intervention, $\beta_{3}$ indicates the slope change following the intervention. $\beta 1+\beta_{3}$ represents the post-intervention trend.

All analyses were performed using R Studio ${ }^{\circledR}$ (RStudio Inc., Boston, MA, USA) version 1.1.456 and SAS software (version 9.2, SAS Institute Inc., NC, USA). The statistically significance was fixed at $p<0.05$.

\section{Results}

\section{Patients, Hand Hygiene and Exposure to Antibiotics}

The patients' characteristics are described in Table 1 for the two periods. 2051 patients had a LOS of more than 2 days (1412 patients for the pre-intervention phase and 640 for the post-intervention phase) 
and were included. Mean age was significantly higher in post-intervention $(+1.8 y e a r s, p=0.02)$.

Table 1

Baseline characteristics in the pre- and post- intervention period

\begin{tabular}{|c|c|c|c|}
\hline Patient characteristics & $\begin{array}{l}\text { Pre intervention } \\
\text { Contact } \\
\text { precaution } \\
(n=1412)\end{array}$ & $\begin{array}{l}\text { Post intervention } \\
\text { Standard } \\
\text { precaution } \\
(n=640)\end{array}$ & $\begin{array}{l}p \\
\text { value }\end{array}$ \\
\hline Age (years) (mean $\left( \pm \mathrm{SD}^{\star}\right)$ ) & $57.6(16.8)$ & $59.4(15.7)$ & 0.02 \\
\hline $\begin{array}{l}\text { Gender, Women (number } \\
(\%))\end{array}$ & $583(41.2 \%)$ & $249(38.9 \%)$ & 0.42 \\
\hline APACHE II, only for ICU patients & $55.6(20.0)$ & $58.8(20.6)$ & 0.07 \\
\hline Length of stay (days) (mean $\left( \pm S D^{\star}\right)$ ) & $12.1(12.5)$ & $12.5(12.4)$ & 0.55 \\
\hline $\begin{array}{l}\text { Antibiotic consumption** (systematic ATC } \\
\text { J01) } \\
(\text { mean }( \pm \text { SD }))\end{array}$ & $1479(136)$ & $1474(269)$ & 0.87 \\
\hline Index of ABHR solution consumption (\%) & 111.1 & 111.8 & 0.94 \\
\hline
\end{tabular}

The monthly ICSHA was constantly higher than $80 \%$. The ICSHA and total antibiotic consumption showed no significant change between intervention periods $(p=0.87$ and $p=0.94$ respectively).

\section{Microbiological Data}

The microbiological data are presented in Table 2. From July 2018 to March 2020, a total of 229 ESBLE positive cultures were documented in the three wards. Rectal swabs were the most positive samples collected (87.8\%). Our main outcome, the mean of ESBLE acquisition ID was 1.32 cases per 1000 patient days $( \pm 1.36)$ during the pre-intervention period versus $1.17( \pm 1.25)$ during the post-intervention period. Concerning the ESBLE importation, the mean of ESBLE importation ID was $1.40( \pm 1.37)$ in preintervention and $1.77( \pm 1.45)$ in post-intervention. We observed a significant increase of first screening (from $37.6-49.3 \%, p<0.001$ ) and completeness of swabs (from 49.2-56.5\%, $\mathrm{p}<0.001$ ). The colonization pressure was higher (13.9\% versus $6.3 \%$ ) during the post-intervention phase. Escherichia coli was the most common ESBL-producing pathogen detected in patients 'samples (39.7\%), with no significant change between the two periods. Followed by Enterobacter cloacae $(26.2 \%)$ significantly less found $(\mathrm{p}=$ 0.01 ) in the post intervention period and Klebsiella pneumoniae(20.1\%). No statistically significant change was observed regarding to the clinical site between the two phases. 
Table 2

Microbiological data samples in the pre- and post-intervention periods

$\begin{array}{lll}\text { Pre intervention } & \text { Post intervention } & \mathbf{p} \\ \text { Value } \\ \text { precaution } & \begin{array}{l}\text { Standard } \\ \text { precaution }\end{array} & \end{array}$

Microbiological data

Number of screening

4942

3901

NA

Positive culture

125

104

NA

History of ESBLE carriage, number

94

62

NA

First screening (ESBLE search $<48$ hours after admission), \%

37.6

49.3

$<$

$(1026 / 2727)$

$(664 / 1346)$

Completeness of swabs, \%

49.2

56.5

$<$

$(4942 / 10035)$

$(3901 / 6900)$

0.001

Colonization pressure, $\%$

6.3

13.9

$<$

0.001

ESBLE by species (\%)

0.03

Escherichia Coli

$36.0(n=45)$

$44.2(n=46)$

0.25

Enterobacter cloacae

$33.6(n=42)$

$17.3(n=18)$

0.01

Klebsiella pneumoniae

$16.0(n=20)$

$25(\mathrm{n}=26)$

0.13

Other ESBLE producers

$14.4(n=18)$

$13.4(n=14)$

0.99

Clinical site (\%)

0.13

Stool

$83.2(n=104)$

$93.2(n=97)$

NA

Urine

$8.0(n=10)$

$3.8(n=4)$

NA

Blood culture

$1.6(\mathrm{n}=2)$

$1.0(\mathrm{n}=1)$

NA

Others

$7.2(\mathrm{n}=9)$

$1.9(n=2)$

NA

NA: not available

Final Model

Series characteristics and trends are presented in Table 3 and represented in Fig. 1. The Durbin-Watson statistic confirmed no autocorrelation (Durbin Watson $1.98<D<2.4$ ) for the models. The SITSA showed no significant change in slope or trend for our main variable, ESBLE acquisition ID $(p=.15)$. We integrated 
the independent variables, which might explain the variations of the acquisition ID, into a SITSA. According to the estimated coefficient reported the post-intervention colonization pressure, acquisition and importation density incidence, and the $\mathrm{HH}$ compliance rates (ICSHA) increased, but no association with significant changes. The only confounding variable with a significant change was the antibiotic consumption, for which slope and trend increased during the post-intervention period $(p=0.04)$.

Table 3

Segmented interrupted regression analysis parameters

\begin{tabular}{|llllll|}
\hline & $\begin{array}{l}\text { Regression } \\
\text { Intercept } \\
\text { (p-value) }\end{array}$ & $\begin{array}{l}\text { Pre- } \\
\text { intervention } \\
\text { trend } \\
\text { (p-value) }\end{array}$ & $\begin{array}{l}\text { Post- } \\
\text { intervention } \\
\text { trend } \\
\text { (p-value) }\end{array}$ & $\begin{array}{l}\text { Level change } \\
\text { after the } \\
\text { intervention } \\
\text { (p-value) }\end{array}$ & $\begin{array}{l}\text { Change in slope } \\
\text { after the } \\
\text { intervention } \\
\text { (p-value) }\end{array}$ \\
\hline $\begin{array}{l}\text { ESBLE acquisition } \\
\text { incidence density * }\end{array}$ & $\begin{array}{l}1.854(< \\
0.001)\end{array}$ & $\begin{array}{l}-0.019 \\
(0.15)\end{array}$ & $0.023(0.41)$ & $-0.018(0.97)$ & $0.043(0.15)$ \\
\hline $\begin{array}{l}\text { ESBLE importation } \\
\text { incidence density * }\end{array}$ & $\begin{array}{l}1.440 \\
0.001)\end{array}$ & $\begin{array}{l}-0.002 \\
(0.91)\end{array}$ & $\begin{array}{l}0.033 \\
(0.25)\end{array}$ & $-0.012(0.86)$ & $0.035(0.25)$ \\
\hline $\begin{array}{l}\text { Colonization } \\
\text { pressure }\end{array}$ & $\begin{array}{l}0.077(< \\
0.001)\end{array}$ & $\begin{array}{l}-0.001 \\
(0.17)\end{array}$ & $\begin{array}{l}0.023 \\
(0.19)\end{array}$ & $0.057(0.12)$ & $0.003(0.12)$ \\
\hline ICSHA* & $\begin{array}{l}114.54(< \\
0.001)\end{array}$ & $\begin{array}{l}-0.519 \\
(0.23)\end{array}$ & $\begin{array}{l}2.545 \\
(0.11)\end{array}$ & $-9.267(0.22)$ & $3.064(0.07)$ \\
\hline $\begin{array}{l}\text { Total antibiotics } \\
\text { use }\end{array}$ & $\begin{array}{l}1386.58(< \\
0.001)\end{array}$ & $\begin{array}{l}15.46 \\
(0.34)\end{array}$ & $\begin{array}{l}17.40 \\
(0.04)\end{array}$ & $-450.97(0.04)$ & $64.16(0.04)$ \\
\hline
\end{tabular}

\section{Discussion}

We observed no significant increase or decrease of acquired ESBL-producing bacteria after the intervention, neither did Thompson \& al (17) when similar interventions were performed. Numerous studies have been reported that nowadays the transmission are predominant in the community $(18,19)$. Acquisition of ESBLE seems to be much more common in the community than in healthcare setting. This statement was verified in our study where the incidence of imported ESBL-producing bacteria is superior to acquired one.

The potential population confounders: the APACHE II, gender and LOS were comparable between the two periods. The patients were significantly older in the post-intervention period, but studies who aimed to investigate the risk factors associated with acquisition of ESBL-producing bacteria did not report the age as one. $(21,22)$ The fact that our study was conducted not only in ICUs (ICUs LOS are 8 days on average) can explained that the LOS observed (12 days throughout both periods) is slightly higher than in others (22). Taking account that the LOS could increase the risk to acquired MDRO (23), our acquisition ID was still comparable to previous findings (24). The ABHR consumption rates were unchanged between the two periods, always above $80 \%$ and consequently showed the adherence in hand hygiene. Finally, the application of SP was also observed through routine audits carried out in wards. 
During the post-intervention phase, the colonization pressure defined by Torres-Gonzales \& al. (16) as a risk factor for MDRO acquisition, was higher, which involve that the cross-infection's risk for a no colonized patient was majored. Alves et al. observed that the LOS and the colonization pressure were positively correlated, which seems to apply in our study.(23) To our knowledge, the present study is one of the first to consider this variable in order to assess its impact in the ESBLE acquisition. The completeness and first screening were significantly better for the CP period, which allowed saying on one hand that the HCWs screenings observance was better and provided a more accurate view of EBLSE colonized patients. On the other hand, we cannot exclude that during the pre-intervention period, HCWs chose to screen only the patients they considered more prone to ESBLE's infections.

Lastly, the antibiotics consumption trend increased significantly during the SP period according to the SITSA. Several findings identified this factor as a risk for ESBLE acquisition and selection, like Graffunder \& al. (20) who documented that in addition of the third-generation cephalosporins, others antibiotics (fluoroquinolones for example) provide selective pressures in maintaining ESBL organisms because of the multiple resistance genes. Moreover, our antibiotic consumption was high comparable with the consumption reported in the Meyer study in ICU (25) and the Tan study in two hematology wards before their intervention on the antibiotics' consumption. (26) This increase could have influenced our ESBLE acquisition ID and could explain the higher trend (not significant) in post-intervention period. This increase might be explained too by the increase of ESBLE ID trend (not significant). Analysis by antibiotics' class could be carried out to confirm our hypothesis.

One of our study's strengths is the approach chosen: the SITSA. This analysis permitted to establish a time dependent relationship and allows forecasting future trends. This method has already been used in others findings $(17,24)$ but not yet using weeks as temporal unit. For our objective, using a weekly data is a strength since the majority of our samples were rectal; and they were supposed to be done on a weekly basis. However, this weekly collection has been also a weakness with regard to missing data when rectal swabs were not performed.

Our study includes some limitations; screenings at admission were not made in a systematic but partial way (37.6\% and $49.3 \%$ respectively for pre and post intervention period). The realization of these samplings depends on the day of admission and that could explain this weakness. (For instance: most of the time the samplings are scheduled on Monday, and if a patient is admitted on Tuesday, the rectal screening will not be taken until six days later). However, some studies did not take into account bacterial carriage at admission thus increasing the possibility of mistakenly identifying community-associated colonization as healthcare-associated after several days of hospitalization $(17,23)$. Moreover, we can point out that since the intervention, the HCWs are more observant with regard to rectal screening: completeness of swabs and screenings at admission have increased significantly. Several potential reasons could explain this increase: just the intervention's consequence but also a new way for stool sample collection at the same time was set up in the hospital and had allowed an easier way to collect samples for the HCWs and to process it for the laboratory. Finally, several studies have questioned the rectal screening's relevance in non-epidemic situations which is in line with our study and the wide 
dissemination in the community.(27) The systematic ESBLE screening could not be adequate anymore to guide contact precautions since the HCWs have just to apply the SP.

Some data risk factors of ESBLE acquisition had not been collected such as the presence of invasive medical devices (central venous or urinary catheters, invasive ventilation...) during the hospitalization and their uses' duration to determine whether there were differences in the two periods based on this factor. Boyer \& al (28) reported an increasing in the uses of medical devices particularly central venous catheters and urinary catheters over their seven years study period but did not speak about the impact of this increase in ESBLE acquisition.

Our post-intervention period's points represent the half of the pre-intervention period's points; because of feasibility issues, we could not continue the data collection due to the COVID-19 epidemic, which would skew the results. According to Zhang \& al. (29) the estimated power for our model with single parameter assuming effect size $=1$, a total sample size of 72 points, and an autocorrelation between -0.2 and 0.2 is between 0.89 and 1 . Our model with more than $80 \%$ of power was able to detect the effects we were looking for. Furthermore, the time series method is the most robust modelling technique (30) for evaluating longitudinal intervention's effect in situations where randomization is not feasible. At the end of the epidemic episode, data collection will be able to resume.

Finally, molecular typing was not performed, and this method could have confirmed the patient-to-patient transmission by identifying the microorganism's genetic.

\section{Conclusion}

Discontinuing contact precaution for patients colonized or infected by ESBLE did not result in a negative outcome; our main variable, the acquisition ID is upwards but not significantly. Our study, confirmed that nowadays the ESBLE are spreading not only in the hospital but also in the community, with an importation ID higher than the acquisition ID. One of the driving factors in order to control the ESBLE nosocomial acquisition could be to improve the use of antibiotics with the intention of decreasing the selective pressure. Monitoring over a longer term is expected.

\section{Abbreviations}

ABHR: Alcohol-based hand rub

APACHE: Acute physiology and chronic health evaluation

CP: Contact precaution

DDD: Defined daily dose

ESBLE: Extended-spectrum $\beta$-lactamase-producing Enterobacteriaceae 
HCWs: Healthcare workers

$\mathrm{HH}$ : Hand hygiene

ICU: Intensive cares unit

ID: Incidence density

IPCT: Infection prevention and control team

ITS: Interrupted time series

LOS: Length of stay

MDRO: Multidrug-resistant organisms

MRSA: Methicillin-resistant Staphylococcus aureus

SITSA: Single interrupted time series analysis

SP: Standard precaution

\section{Declarations}

Ethics approval and consent to participate:

not applicable

Consent for publication:

not applicable

Availability of data and materials:

All data generated or analyzed during this study are included in this published.

Competing interests:

The authors declare that they have no competing interests.

Funding:

No funding reported.

Authors' contributions: 
Conceptualization, MR, LR AF; Methodology, MR, AF; Formal Analysis, MR; Investigation, MR Data Curation, MR; Writing-Original Draft Preparation, MR; Writing-Review and Editing, JL, LR, AF, BL, CJ; Visualization, MR; Supervision, AF; Project Administration, AF.

\section{Acknowledgements:}

The authors thank the members of the infection prevention and control team and the healthcare professionals who participated in the survey.

\section{References}

1. Cordery RJ, Roberts $\mathrm{CH}$, Cooper SJ, Bellinghan G, Shetty N. Evaluation of risk factors for the acquisition of bloodstream infections with extended-spectrum beta-lactamase-producing Escherichia coli and Klebsiella species in the intensive care unit; antibiotic management and clinical outcome. $J$ Hosp Infect. feb 2008;68(2):108-15.

2. Santé publique France. Surveillance des bactéries multi résistantes dans les établissements de santé en France : Réseau BMR-Raisin - Résultats 2017

3. Baur D, Gladstone BP, Burkert F, Carrara E, Foschi F, Döbele S, et al. Effect of antibiotic stewardship on the incidence of infection and colonisation with antibiotic-resistant bacteria and Clostridium difficile infection: a systematic review and meta-analysis. Lancet Infect Dis. 2017;17(9):990-1001.

4. Société française d'hygiène hospitalière. Recommandations nationales - Prévention de la transmission croisée : précautions complémentaires contact - Consensus formalisé d'experts. Hygiènes 2009; 17(2): 1-81..7.

5. Kim N-H, Han W-D, Song K-H, Seo H-K, Shin M, Kim TS, et al. Successful containment of carbapenemresistant Enterobacteriaceae by strict contact precautions without active surveillance. Am J Infect Control. dec 2014;42(12):1270-3.

6. Observatoire National de l'Epidémiologie de la Résistance Bactérienne aux Antibiotiques - Rapport 2017

7. Mehrotra P, Croft L, Day HR, Perencevich EN, Pineles L, Harris AD, et al. Effects of Contact Precautions on Patient Perception of Care and Satisfaction: A Prospective Cohort Study. Infect Control Hosp Epidemiol. oct 2013;34(10):1087-93.

8. Zahar JR, Garrouste-Orgeas M, Vesin A, Schwebel C, Bonadona A, Philippart F, et al. Impact of contact isolation for multidrug-resistant organisms on the occurrence of medical errors and adverse events. Intensive Care Med. déc 2013;39(12):2153-60.

9. Sprague E, Reynolds S, Brindley P. Patient Isolation Precautions: Are They Worth It? Can Respir J. 2016;2016:5352625.

10. Société française d'hygiène hospitalière. Recommandations nationales - Actualisation des précautions standard. Consensus formalisé d'experts. Hygiènes Juin 2017: 1-68. 
11. Bruyère R, Vigneron C, Bador J, Aho S, Toitot A, Quenot J-P, et al. Significance of Prior Digestive Colonization With Extended-Spectrum $\beta$-Lactamase-Producing Enterobacteriaceae in Patients With Ventilator-Associated Pneumonia. Crit Care Med. apr 2016;44(4):699-706.

12. Carbonne H, Le Dorze M, Bourrel A-S, Poupet H, Poyart C, Cambau E, et al. Relation between presence of extended-spectrum $\beta$-lactamase-producing Enterobacteriaceae in systematic rectal swabs and respiratory tract specimens in ICU patients. Ann Intensive Care. dec 2017;7(1):13.

13. Instruction DGOS/PF2 n 2015-67 du 11 mars 2015 relative au bilan des activités de lutte contre les infections nosocomiales dans les établissements de santé pour l'année 2014, (2015).

14. Haute Autorité de Santé. Grille de recueil, consignes d'aide au remplissage et éléments de preuve 2019. Thème Infections Associées aux Soins (IAS) ICSHA.3 Mars 2019

15. Bonten MJ, Slaughter S, Ambergen AW, Hayden MK, van Voorhis J, Nathan C, et al. The role of « colonization pressure » in the spread of vancomycin-resistant enterococci: an important infection control variable. Arch Intern Med. 1998;158(10):1127-32.

16. Torres-Gonzalez P, Cervera-Hernandez ME, Niembro-Ortega MD, Leal-Vega F, Cruz-Hervert LP, GarcíaGarcía L, et al. Factors Associated to Prevalence and Incidence of Carbapenem-Resistant Enterobacteriaceae Fecal Carriage: A Cohort Study in a Mexican Tertiary Care Hospital. PLoS ONE. 2015;10(10):e0139883.

17. Thompson P, Teter J, Atrubin K. Incidence of healthcare-associated extended-spectrum $\beta$-lactamasepositive patients before and after discontinuation of contact precautions. Am J Infect Control. 2019.

18. Rodriguez-Villalobos H, Bogaerts P, Berhin C, Bauraing C, Deplano A, Montesinos I, et al. Trends in production of extended-spectrum beta-lactamases among Enterobacteriaceae of clinical interest: results of a nationwide survey in Belgian hospitals. J Antimicrob Chemother. jan 2011;66(1):37-47.

19. Haverkate MR, Platteel TN, Fluit AC, Cohen Stuart JW, Leverstein-van Hall MA, Thijsen SFT, et al. Quantifying within-household transmission of extended-spectrum $\beta$-lactamase-producing bacteria. Clin Microbiol Infect. jan 2017;23(1):46.e1-46.e7.

20. Graffunder EM, Preston KE, Evans AM, Venezia RA. Risk factors associated with extended-spectrum beta-lactamase-producing organisms at a tertiary care hospital. J Antimicrob Chemother. 2005;56(1):139-45.

21. Augustine MR, Testerman TL, Justo JA, Bookstaver PB, Kohn J, Albrecht $H$, et al. Clinical Risk Score for Prediction of Extended-Spectrum $\beta$-Lactamase-Producing Enterobacteriaceae in Bloodstream Isolates. Infect Control Hosp Epidemiol. 2017;38(3):266-72.

22. Renaudin L, Llorens M, Goetz C, Gette S, Citro V, Poulain S, et al. Impact of Discontinuing Contact Precautions for MRSA and ESBLE in an Intensive Care Unit: A Prospective Noninferiority Before and After Study. Infect Control Hosp Epidemiol. 2017;38(11):1342-50.

23. Alves M, Lemire A, Decré D, Margetis D, Bigé N, Pichereau C, et al. Extended-spectrum beta-lactamase - producing enterobacteriaceae in the intensive care unit: acquisition does not mean crosstransmission. BMC Infect Dis [Internet]. 2016 
24. Kaier K, Frank U, Hagist C, Conrad A, Meyer E. The impact of antimicrobial drug consumption and alcohol-based hand rub use on the emergence and spread of extended-spectrum beta-lactamaseproducing strains: a time-series analysis. J Antimicrob Chemother. mar 2009;63(3):609-14.

25. Meyer E, Lapatschek M, Bechtold A, Schwarzkopf G, Gastmeier P, Schwab F. Impact of restriction of third generation cephalosporins on the burden of third generation cephalosporin resistant $\mathrm{K}$. pneumoniae and E. coli in an ICU. Intensive Care Med. 2009;35(5):862-870. doi:10.1007/s00134-008$1355-6$

26. Tan BH, Guzman MRT, Donato LKS, Kalimuddin S, Lee WHL, Tan AL, Wong GC. Impact of an alternating first-line antibiotics strategy in febrile neutropenia. PLoS One. $2018 ; 28 ; 13(11)$ :e0208039.

27. Prevel, R., Boyer, A., M'Zali, F. et al. Is systematic fecal carriage screening of extended-spectrum betalactamase-producing Enterobacteriaceae still useful in intensive care unit: a systematic review. Crit Care 23, 170 (2019). https://doi.org/10.1186/s13054-019-2460-3

28. Boyer A, Couallier V, Clouzeau B, Lasheras A, M'zali F, Kann M, et al. Control of extended-spectrum $\beta$ lactamase-producing Enterobacteriaceae nosocomial acquisition in an intensive care unit: A time series regression analysis. Am J Infect Control. 1 déc 2015;43(12):1296-301.

29. Zhang F, Wagner AK, Ross-Degnan D. Simulation-based power calculation for designing interrupted time series analyses of health policy interventions. J Clin Epidemiol. nov 2011;64(11):1252-61.

30. Crabtree BF, Ray SC, Schmidt PM, O'Connor PJ, Schmidt DD. The individual over time: time series applications in healthcare research. J Clin Epidemiol. 1990;43(3):241-60.

\section{Figures}




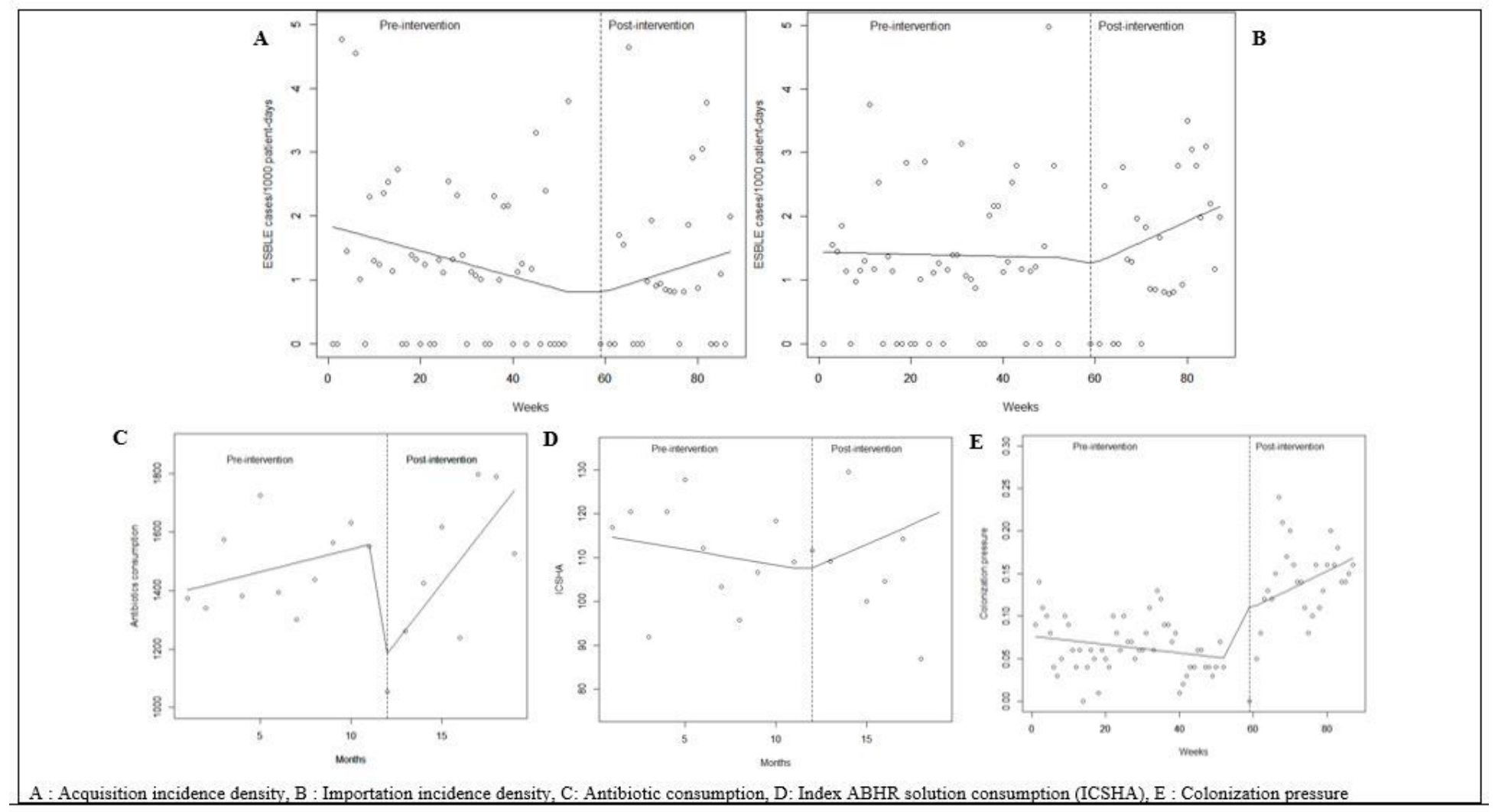

Figure 1

Changes in variables before and after the intervention 